\title{
Predictors for Adverse Outcome in Patients Aged 80 Years and Older Undergoing Emergent Hip Surgery
}

\author{
Eli Peled ${ }^{1}$, Michal Barak ${ }^{2}$, Yaniv Keren ${ }^{3}$, Michael Soudry ${ }^{3}$, Doron Norman ${ }^{1}$ \\ ${ }^{1}$ Departments of Orthopedic Surgery B, Rambam Health Care Campus and the Bruce Rappaport Faculty \\ of Medicine, Technion-Israel Institute of Technology, Haifa, Israel \\ ${ }^{2}$ Departments of Anesthesia, Rambam Health Care Campus and the Bruce Rappaport Faculty of Medicine, \\ Technion-Israel Institute of Technology, Haifa, Israel \\ ${ }^{3}$ Departments of Orthopedic Surgery A, Rambam Health Care Campus and the Bruce Rappaport Faculty \\ of Medicine, Technion-Israel Institute of Technology, Haifa, Israel \\ E-mail:m_barak@rambam.health.gov.il \\ Received June 10, 2011; revise-d September 14, 2011; accepted October 14, 2011
}

\begin{abstract}
Background: Increased life expectancy results in aging of the population. One of the leading medical problems of elderly patients is hip fracture. We studied demographic, surgical and anesthetic parameters of elderly patients who underwent surgery due to osteoporotic hip fracture, to find predictors for peri-operative morbidity and mortality. Methods: This is a retrospective review of prospectively collected data of patients aged 80 years and older who underwent emergent surgery due to osteoporotic femoral neck, subcapital or pertrochanteric fractures. Data was collected on age, gender, co-morbidities, American Society of Anesthesiologists Class, number of regular medications, whether the patient was bedridden or not before the surgery, hemoglobin on admission and on discharge, type of surgery and anesthesia, duration of surgery, duration of hospitalization, post-operative morbidity and mortality. The demographic and peri-operative parameters were analyzed and matched to the post-operative complications and mortality to find predictors for adverse outcome. Results: One hundred and nine patients were included in the study, of whom $22(20 \%)$ had post-operative complications and $10(9.1 \%)$ died. We found an increased complication rate in patients who had chronic obstructive pulmonary disease and in patients who underwent general anesthesia. Patients who were bedridden before the surgery had increased mortality rates. No significant correlation was found between outcome and any other factors. Conclusion: Our results suggest favoring regional anesthesia in elderly patients undergoing emergent femoral neck surgery and acknowledging a higher risk in chronic pulmonary disease or bedridden patients.
\end{abstract}

Keywords: Femoral Fracture, Surgery, Orthopedics, Anesthesia, Spinal, Complications, Postoperative

\section{Introduction}

Osteoporotic hip fracture is a major health problem worldwide [1]. Its incidence has been rising steadily, mainly due to increased life expectancy [1,2], and this trend is expected to continue in the future. There were 1.6 million osteoporotic hip fractures throughout the world in 2000 [1] and it has been estimated that the number of hip fractures in 2025 will be 2.6 million and in 2050 will be 4.5 million [3]. The age of the patients has been increasing as well. Although age is recognized as a significant risk factor for complications and mortality [4,5], there is no recommendation to avoid surgery at any age $[6,7]$. In this study we focused on the elderly population, patients aged 80 years or more, in order to isolate age from other risk factors. We believe that patients in this age group constitute a distinct entity, with typical physiology and unique medical characteristics and needs. We prospectively followed their management during surgery and hospital stay to find predictors for adverse outcome, in the hope that this could lead to better management of these patients in the future, although it is still uncertain whether or not their outcome is modifiable [8].

\section{Patients and Methods}

With the approval of the local Ethics Committee, we conducted this study, a retrospective review of prospec- 
tively collected data of patients 80 years old or older who underwent emergent orthopedic surgery for osteoporotic femoral neck fracture in our institution. The surgery took place within less than 48 hours from admission to the emergency room. All the patients were assessed preoperatively by an anesthesiologist who determined their American Society of Anesthesiologists (ASA) class and planned the type of anesthesia and the level of operative and post-operative monitoring. The anesthesia of choice was regional, specifically spinal. Only patients who had a contraindication for regional anesthesia, such as abnormal coagulation blood tests, had general anesthesia.

In the operating room, the patients were monitored and treated according to their general condition and the sequence of the surgery. The senior orthopedic surgeon decided, according to the fracture type, whether to do a partial hip replacement (PHR) or reduction and internal fixation. Displaced sub-capital fractures, Garden III \& IV, were replaced, while nondisplaced sub-capital fractures, Garden I \& II, were stabilized by three $7.3 \mathrm{~mm}$ cannulated screws (CS). Femoral and intertrochanteric fractures were reduced by closed or open means and were stabilized by dynamic hip screw (DHS) or proximal femoral nail (PFN). All the patients were admitted to the post-anesthesia care unit following surgery, where they stayed for two hours or more, depending on their general condition. In cases of hemodynamic instability, respiretory problem, or intra-operative complication, the patient was transferred to the intensive care unit. Patients who underwent uneventful surgery were transferred 7 - 9 days later to another institution for rehabilitation. Follow-up continued during their hospitalization time.

Collected data included age, gender, co-morbidities: hypertension, ischemic heart disease, diabetes mellitus, chronic obstructive pulmonary disease (COPD), other co-morbidity, number of medications that the patient used regularly before admission to hospital, whether or not the patient was bedridden before the surgery, ASA class, hemoglobin on admission and on discharge and the disparity between them, type of surgery (PHR, DHS, CS PFN), duration of surgery, type of anesthesia, duration of hospitalization, 30 day post-operative morbidity, and mortality within six months of surgery. Morbidity was defined as a new disease or illness (new diagnosis) that occurred in the peri-operative peiod, meaning within a month from surgery. We analyzed the data and studied correlations between each and every pre- and intra-operative parameter to post-operative morbidity and mortality, in order to find predictors for adverse outcome.

\section{Statistical Analysis}

Data was analyzed with a commercial statistical software
(Statistica 6.0, StatSoft, Tulsa OK). Frequencies were compared using Pearson's chi square test. Continuous variables were compared using analysis of variance. Whenever the homogeneity of variance was violated (significant Levene's test), the Mann-Whitney test was applied instead. Pre-post comparisons used the $t$-test for dependent variables. Significance level was set at $\mathrm{p}<$ 0.05 .

\section{Results}

One hundred and nine patients were included in the study, $32(29 \%)$ male and $77(71 \%)$ female. Age ranged between 80 to 98 years (median 85); there was no significant age difference between genders. Patients' co-morbidities are summarized in Table 1.

The type of surgery was PHR in 29 (26.6\%) patients and CS or DHS or PFN in 80 (73.3\%) patients. In Table 2 we compared patients who underwent PHR to those who had CS or DHS or PFN. Spinal anesthesia was used in $95(87.2 \%)$ patients and general anesthesia in 14 $(12.8 \%)$ patients.

The contraindication for regional anesthesia in all the patients who underwent general anesthesia was the use of anticoagulants or anti-platelet aggregation drugs, other than acetylsalicylic acid.

Mean length of hospital stay was 7.6 days (SD 3.5 days).

Twenty-two $(20 \%)$ patients had post-operative complications and $10(9.1 \%)$ patients died. Post-operative complications are summarized in Table 3.

Predictors for adverse outcome: patients with COPD had significantly higher rates of post-operative complications than other patients $(p=0.001)$. The complication rate was significantly higher in patients who had general anesthesia (35\%) compared to those who had spinal an-

Table 1. Patient co-morbidities and pre-operative data.

\begin{tabular}{lc}
\hline & Number of Patients (\%) \\
\hline Hypertension & $87(81 \%)$ \\
Ischemic heart disease & $44(41 \%)$ \\
Diabetes mellitus & $26(24 \%)$ \\
Chronic obstructive pulmonary disease & $7(6.5 \%)$ \\
$\begin{array}{l}\text { Other co-morbidities } \\
\text { Patient bedridden }\end{array}$ & $83(77.5 \%)$ \\
$\begin{array}{l}\text { American Society of Anesthesiology } \\
\text { (ASA) class, Mean ( } \pm \text { SD) }\end{array}$ & $14(13 \%)$ \\
$\begin{array}{l}\text { Number of regular medications used, } \\
\text { Mean ( } \pm \text { SD) }\end{array}$ & $2.8( \pm 0.7)$ \\
$\begin{array}{l}\text { Pre-operative hemoglobin }(\mathrm{g} \%) * \text { Mean } \\
\text { (range) }\end{array}$ & $5.3( \pm 3.2)$ \\
\hline
\end{tabular}

*Normal range is $12.0-16.0 \mathrm{~g} \%$. 
Table 2. Patients who underwent partial hip replacement (PHR) compared with patients who underwent cannulated screw (CS), dynamic hip screw (DHS) or proximal femoral nail (PFN).

\begin{tabular}{cccc}
\hline & $\begin{array}{c}\text { PHR } \\
(\mathbf{N}=\mathbf{2 9}, \\
\text { Mean } \pm \text { SD) }\end{array}$ & $\begin{array}{c}\text { CS or DHS or } \\
\text { PFN (N=80, } \\
\text { Mean } \pm \text { SD) }\end{array}$ & Significance \\
\hline Age (years) & $85 \pm 5.1$ & $86.3 \pm 4.3$ & NS \\
$\begin{array}{c}\text { Duration of surgery } \\
\text { (minutes) }\end{array}$ & $47 \pm 8$ & $61 \pm 29$ & $p=0.008^{*}$ \\
Hospital stay (days) & $7.0 \pm 2.7$ & $7.4 \pm 3.7$ & NS \\
Complications (\%) & $16 \%$ & $20 \%$ & $\mathrm{NS}$ \\
Mortality (\%) & $15.4 \%$ & $8.7 \%$ & $\mathrm{NS}$ \\
\hline
\end{tabular}

Notes: $\mathrm{N}=$ number of patients; $\mathrm{SD}=$ standard deviation; $\mathrm{NS}=$ not significant statistically; *Applying the Mann-Whitney test.

Table 3. Postoperative complications.

\begin{tabular}{ll}
\hline Respiratory complications & Number \\
\hline Pneumonia & 1 \\
Pleural effusion & 1 \\
Respiratory failure & 2 \\
Cardiac complications & \\
$\quad$ Acute MI & 1 \\
Acute atrial fibrillation & 1 \\
Neurological complications & \\
CVA & 1 \\
Delirium & 1 \\
Parasthesia & 1 \\
Infectious complications & \\
Infection & 3 \\
UTI & 3 \\
Sepsis & 1 \\
Renal failure & 3 \\
Loosening of prosthesis and re-operation & 1 \\
Bleeding & 1 \\
Bleeding in surgical site & \\
Rectal bleeding &
\end{tabular}

Notes: MI = myocardial infarction; $\mathrm{CVA}=$ cerebral vascular accident; UTI $=$ urinary tract infection.

esthesia $(16 \%), p=0.044$. Mortality was higher in general anesthesia (14\%) than in spinal anesthesia (9\%) but this was not statistically significant $(p=0.5)$. Death was significantly higher in the bedridden group of patients $(28.6 \%)$ than in ambulant patients $(6.45 \%), p=0.008$.

As expected, hospitalization was significantly longer in patients with complications than in those without complications. Also, the mortality rate was significantly higher in the group of patients who had a complication than in patients who had uneventful surgery $(p=0.016)$.

\section{Discussion}

Increased life expectancy is an indicator of improved life style and good health services. Yet, aging of the population establishes a challenge to the medical profession. Patients 80 year old and more require special management, as all body systems undergo physiological deterioration during these years. Cardiovascular, pulmonary and central nervous systems show considerable decline, as do liver and kidney functions, and metabolic and endocrine systems [9-12]. Progressive osteoporosis and reduced muscle mass cause frailty [13]; hence, bone fracture is a leading health problem in this age group [14]. Often, these patients are treated with many drugs, suffer malnutrition and electrolyte disturbances, and a notable number of them are bedridden $[15,16]$. Elderly patients have reduced drug metabolism and elimination [17]. As a result of all this, anesthesia for elderly patients is complex. Surgery is more complicated as patients age. Osteoporotic bones raise technical difficulties with keeping the fracture reduced and stable enough to allow patients to ambulate. It is not uncommon to lose reduction and fixation during the postoperative and rehabilitation periods due to the bone quality of older patients. Failure of fixation or weak bone purchase prevents ambulation which is not easy after such a fracture. Thus, postoperative recovery and rehabilitation is slow and demanding.

In this study, we found a significant higher complication rate in patients who had general anesthesia compared with spinal anesthesia. We also found a higher mortality rate in general anesthesia than in spinal anesthesia, although this was not statistically significant. The issue of general versus regional, specifically spinal, anesthesia was studied in the past, although the literature is not unanimous. In a large retrospective study of 9425 patients who underwent hip surgery in 1983-1993, the 30 -day mortality rate in the general anesthesia group was $4.4 \%$, compared with $5.4 \%$ in the regional anesthesia group [18]. Contradicting results were found in a metaanalysis of 15 trials comparing general to regional anesthesia, where regional anesthesia was associated with decreased mortality at one month, yet the statistical significance was borderline [19]. In an early prospective study of 578 patients aged 50 and more who underwent hip surgery, the difference in postoperative mortality after spinal versus general anesthesia was statistically insignificant [20]. Koval et al. conducted a prospective randomized study of 749 patients undergoing hip surgery and found no significant difference in inpatient morbidity and mortality between patients receiving general or spinal anesthesia [21]. Based on our results, we suggest that 
general anesthesia carried an increased complication risk compared with spinal anesthesia in the selected group of patients aged 80 years or more.

In addition, we found that COPD significantly increased the risk of postoperative complications in this group of elderly patients. The causative association between COPD and hip fracture is well known since COPD patients who are treated with systemic corticosteroids are at a higher risk for osteoporotic fractures [22]. However, their higher risk for poor outcome was only recently acknowledged. In 2002, Eisler et al. found that only COPD significantly affected functional recovery at three months after hip surgery [23]. Later, de Luise et al found that patients with COPD had a $60 \%-70 \%$ higher risk of death following hip fracture than those without COPD [24]. These authors suggested that certain diseases are more strongly associated with mortality than others, since they profoundly affect the maintenance of normal physiology, as does the cardiopulmonary system.

In summary, elderly patients are more vulnerable than younger patients, and their recovery ability is damaged. Every single complication may deteriorate the patient gravely. This is supported by our finding that the mortality rate was significantly higher in the group of patients who had a complication than in patients who had an uneventful procedure. Thus, prompt and intensive reaction to a change in patient status is required. The recognition of elderly patients as a distinct group with certain medical and surgical characteristics and needs is essential for future improvement of care.

\section{References}

[1] O. Johnell and J. A. Kanis, "An Estimate of the Worldwide Prevalence and Disability Associated with Osteoporotic Fractures," Osteoporosis International, Vol. 17, No. 12, 2006, pp. 1726-1733. doi:10.1007/s00198-006-0172-4

[2] C. Holroyd, C. Cooper and E. Dennison, "Epidemiology of Osteoporosis," Best Practice \& Research Clinical Endocrinology \& Metabolism, Vol. 22, No. 5, 2008, pp. 671-685. doi:10.1016/j.beem.2008.06.001

[3] B. Gullberg, O. Johnell and J. A. Kanis, "World-Wide Projections for Hip Fracture," Osteoporosis International, Vol. 7, No. 5, 1997, pp. 407-413. doi:10.1007/PL00004148

[4] M. Bhandari, H. Koo, L. Saunders, S. G. Shaughnessy, R. B. Dunlop and E. H. Schemitsch, "Predictors of In-Hospital Mortality Following Operative Management of Hip Fractures," International Journal of Surgical Investigation, Vol. 1, No. 4, 1999, pp. 319-326.

[5] M. Cree, C. L. Soskolne, E. Belseck, J. Hornig, J. E. McElhaney, R. Brant and M. Suarez-Almazor, "Mortality and Institutionalization Following Hip Fracture," Journal of the American Geriatrics Society, Vol. 48, No. 3, 2000, pp. 283-288.

[6] E. Bergeron, L. Moore, K. Fournier, C. Gravel and A. Lavoie, "Patients with Isolated Hip Fracture must be Considered for Surgery Irrespectively of their Age, Comorbidity Status and Provenance: A Statement Applicable even to Nonagerians," Archives of Orthopedic and Trauma Surgery, Vol. 129, No. 11, 2009, pp. 1549-1555. doi:10.1007/s00402-009-0888-7

[7] A. D. Pelavski, M. J. Colomina, M. De Miguel M. E. Marquez, C. Dolors and M. Aranda, "Demographics of Nonagenarians and Centenarians with a Hip Fracture," Anesthesia and Analgesia, Vol. 103, No. 6, 2006, pp. 1597-1599. doi:10.1213/01.ane.0000246354.21634.30

[8] G. G. Teng, J. R. Curtis and K. G. Saag, "Mortality and Osteoporotic Fractures: Is the Link Causal, and Is It Modifiable?" Clinical and Experimental Rheumatology, Vol. 26, No. 5, 2008, pp. S125-137.

[9] A. F. Kramer, K. I. Erickson and S. J. Colcomb, "Exercise, Cognition, and the Aging Brain," Journal of Applied Physiology, Vol. 101, No. 4, 2006, pp. 1237-1242. doi:10.1152/japplphysiol.00500.2006

[10] P. E. Krumpe, R. J. Knudson, G. Parsons and K. Reiser, "The Aging Respiratory System," Clinics in Geriatric Medicine, Vol. 1, No. 1, 1985, pp. 143-175.

[11] H. J. Priebe, "The Aged Cardiovascular Risk Patient," British Journal of Anaesthesia, Vol. 85, No. 5, 2000, pp. 763-778. doi:10.1093/bja/85.5.763

[12] D. L. Schmucker, "Age-Related Changes in Liver Structure and Function: Implications for Disease?" Experimental Gerontology, Vol. 40, No. 8-9, 2005, pp. 650-659. doi:10.1016/j.exger.2005.06.009

[13] M. Maggio, A. R. Cappola, G. P. Ceda, S. Basaria, C. W. Chia, G. Valenti and L. Ferrucci, "The Hormonal Pathway to Frailty in Older Men," Journal of Endocrinological Investigation, Vol. 28, No. 11, 2005, pp. 15-19.

[14] L.A. Beaupre, C. A. Jones, L. D. Saunders, D. W. Johnston, J. Buckingham and S. R. Majumdar, "Best Practices for Elderly Hip Fracture Patients. A Systematic Overview of the Evidence," Journal of General Internal Medicine, Vol. 20, No. 11, 2005, pp. 1019-1025. doi:10.1111/j.1525-1497.2005.00219.x

[15] L. H. Beck, "The Aging Kidney. Defending a Delicate Balance of Fluid and Electrolytes," Geriatrics, Vol. 55, No. 4, 2000, pp. 26-28.

[16] B. J. Rolls and P. A. Phillips, "Aging and Disturbances of Thirst and Fluid Balance," Nutrition Reviews, Vol. 48, No. 3, 1990, pp. 137-144. doi:10.1111/j.1753-4887.1990.tb02915.x

[17] R. Rivera and J. F. Antognini, "Perioperative Drug Therapy in Elderly Patients," Anesthesiology, Vol. 110, No. 5, 2009, pp. 1176-1181. doi:10.1097/ALN.0b013e3181a10207

[18] D. A. O'Hara, A. Duff, J.A. Berlin, R.M. Poses, V.A. Lawrence, E.C. Huber, H. Noveck, B.L. Strom and J.L. Carson," The Effect of Anesthetic Technique on Postoperative Outcomes in Hip Fracture Repair," Anesthesiol- 
ogy, Vol. 92, No. 4, 2000, pp. 947-957.

[19] M. J. Parker, S. C. Urwin, H. H. Handoll and R. Griffith, "General versus Spinal/Epidural Anaesthesia for Surgery for Hip Fractures in Adults," Cochrane Database of Systematic Reviews, Vol. 2, 2000, p. CD000521.

[20] N. Valentin, B. Lomholt, J. S. Jensen, N. Hejgaard and S. Kreiner, "Spinal or General Anaesthesia for Surgery of the Fractured Hip? A Prospective Study of Mortality in 578 Patients," British Journal of Anaesthesia, Vol. 58, No. 3, 1986, pp. 284-291. doi:10.1093/bja/58.3.284

[21] K. J. Koval, G. B. Aharonoff, A. D. Rosenberg, C. Schmigelski, R. L. Bernstein and J. D. Zuckerman, "Hip Fracture in the Elderly: The Effect of Anesthetic Technique," Orthopedics, Vol. 22, No. 1, 1999, pp. 31-34.

[22] G. T. Ferguson, P. M. Calverley, J. A. Anderson, C. R.
Jenkins, P. W. Jones, L. R. Willits, J. C. Yates, J. Vestbo and B. Celli, "Prevalence and Progression of Osteoporosis in Patients with COPD: Results From the Towards a Revolution in COPD Health Study," Chest, Vol. 136, No. 6, 2009, pp. 1456-1465. doi:10.1378/chest.08-3016

[23] J. Eisler, R. Cornwall, E. Strauss, K. Koval, A. Siu and M. Gilbert, "Outcomes of Elderly Patients with Nondisplaced Femoral Neck Fractures," Clinical Orthopaedics and Related Research, Vol. 399, 2002, pp. 52-58.

[24] C. de Luise, M. Brimacombe, L. Pedersen and H. T. Sorensen, "Chronic Obstructive Pulmonary Disease and Mortality Following Hip Fracture: A Population-Based Cohort Study," European Journal of Epidemiology, Vol. 23, No. 2, 2008, pp. 115-122. doi:10.1007/s10654-007-9211-5 